\title{
Spectroscopy Analysis of Silver Nanoparticles Synthesized from citrus Limon Leaf Extract and Their Biological Effects
}

\author{
Khane Yasmina $^{1,2^{*}}$, Benouis Khedidja ${ }^{3}$, Metiaz Hadj Mohammed ${ }^{1}$, Boudiba \\ Ahlem $^{1}$, Khane Sofiane ${ }^{4}$, Djaber Aouf ${ }^{5}$, Fenniche Fares ${ }^{5}$, Messaouda Matallah ${ }^{6}$ \\ ${ }^{1}$ Université de Ghardaia, BP 455, 47000 Ghardaïa, Algerie \\ ${ }^{2}$ Laboratoire de chimie appliqué. ACTR Univ Ain Temouchent, Bp 284, 46000 Ain Temouchent \\ ${ }^{3}$ Laboratory of process engineering, materials and environment, Department of Energy and Process \\ Engineering, Faculty of Technology, University of Djillali Liabes, Sidi Bel Abbes, PO Box89 SBA 22000 - \\ Algeria \\ ${ }^{4}$ Université de Djillali liabes, Faculté des sciences exacte, Sidi Bel Abbes \\ ${ }^{5}$ Laboratory of Dynamic Interactions and Reactivity of Systems, University of Kasdi Merbah, 30000 Ouargla. \\ ${ }^{6}$ Université Amar Telidji, Laghouat, Ageria. \\ *Corresponding author. Email: yasminekhane@yahoo.fr or khane.yasmina@univ-ghardaia.dz.
}

\begin{abstract}
Due to its efficiency, eco-friendliness, non-toxicity, and cost-effectiveness, the utilisation of plant extracts in the manufacture of silver nanoparticles has garnered attention. The purpose of this study is to determine the feasibility of generating silver nanoparticles from an aqueous extract of Citrus limon leaves and their size and composition was characterized utilizing UV visible, FTIR, SEM, EDX, and Zeta seizer. Additionally, the antioxidant efficacy of Ag NPs was tested using the DPPH radical scavenging method, and their antibacterial activity was verified in vitro using the Agar well diffusion technique. Silver nanoparticles were successfully synthesized and exhibit surface plasmon resonance with an absorption maximum of $475.2 \mathrm{~nm}$ and the stabilization of the ions Ag to nanometric spherical negative charge particles, as verified by FTIR, MEB, EDX, and Zeta potential values. Furthermore, the silver nanoparticles created displayed a substantial bactericidal effect against the three types of bacteria (Escherichia coli, Pseudomonas aeruginosa, and Staphylococcus aureus) and an antifungal activity against (Candida albicans) as well as reasonable antioxidant properties.
\end{abstract}

Keywords: leaves, citrus limon, silver nanoparticles, biosynthesis, biological activity.

\section{INTRODUCTION}

Silver nanoparticles (AgNPs) produced through greener approach without use any toxic chemicals additive was proved to be the rapid, economic and environmentally biosynthetic procedure [1] for exploit the AgNPs for biomedical, therapeutic and Food Safety applications [2]. In the recent years, Several research have been explored that the production of biosynthesis AgNPs utilizing a variety of plant extract such as Euphrasia officinalis [3], Cestrum nocturnum [4], Dillenia indica [5], Punica granatum [6],
Mimusops elengi fruit [7] due to their richness in phytochemicals compounds [8] which play a major role as bioreduction and stabilizing [9]. Furthermore, these compounds can also modify and alter the properties of nanoparticles to improve their performance for different applications [10-11]. For that the plants having pharmacological properties attracted a lot of attention for synthesis a green silver nanoparticle with a significant anticancer, [7] antioxidant, antimicrobial, antifungal, antiproliferative and cytotoxic activity [12-15]. 
The lemon is the fruit of the lemon tree (Citrus lemon), which belongs to the Rutaceae family, originally from Southeast Asia, and is now widely planted throughout the Mediterranean littoral and anywhere else with a semi-tropical climate [16]. The leaves of citrus limon is known with a significant pharmacological and therapeutical important to improve the human health such as anti-tumor, antioxidative, anticancer, antiinflammatory, and antimicrobial activity due to heigh richess with secondary metabolites like flavonoids, phenolic acids, carboxylic acids, vitamins and other compounds [17-19]. These properties encourage as for use the citrus limon leaf extract for synthesis a silver nanoparticle with antioxidant and antimicrobial activity.

\section{EXPRIMENTAL METHODS}

\subsection{Preparation of Citrus limon leaf}

During the month of January 2020, a collection of citrus limon (C. limon) leaves was picked by hand from a local public farm in Daia Ben Dahoua, a modest neighborhood in the city of Ghardaïa located in northern-central Algeria. Before using, the selected leaves must be thoroughly rinsed many times with water, then with deionized water to clean any residuals dust and dirt from the surface, and then dried at room temperature.

\subsection{Preparation aqueous extract of the Citrus limon leaf}

After 15 minutes, $15 \mathrm{~g}$ of citrus limon dried leaves were extracted by refluxing in $150 \mathrm{ml}$ of distlled water at $65{ }^{\circ} \mathrm{C}$. A pale yellow extract was filtered, and then saved at $6{ }^{\circ} \mathrm{C}$ until used in the next step.

\subsection{Green synthesis of AgNPs}

$80 \mathrm{ml}$ of $1 \mathrm{mM}$ silver nitrate was mixed with $80 \mathrm{ml}$ of aqueous citrus limon leaf extract solution and agitated continuously at $65^{\circ} \mathrm{C}$ for 2,5 hour. The yellow mixture became turbid and changed to brown, which displayed that the silver nanoparticles had formed. AgNPs were next purified by centrifuging the colloidal solution for 20 minutes at $15000 \mathrm{tr} / \mathrm{min}$, and yielding a dark brown precipitate that was washed with doubly sterilized water and subsequently with methanol. Finally, silver nanoparticles were obtained by drying the powder precipitate and we used UV-Visible spectroscopy to control the formation of AgNPs.

\subsection{Spectroscopy analysis of AgNPs}

The biosynthesized AgNPs were investigated by determining the surface plasmon resonance SPR using UV-vis spectrophotometry (UviLine 9400C). To characterize the biofunctional groups existing in the extract of citrus limon leaf, that contribute significantly in the bioreduction of silver to form silver nanoparticles, FT-IR spectroscopy analysis was done using an Agilent Cary 640 FTIR spectrometer. The morphology, the elemental composition and the Zeta potential values of AgNPs was evaluated using scanning electron microscopy (SEM) combined with an energy dispersive X-ray spectrometer (EDX) model JSM-5910 (JEOL) and a nano zetasizer instrument (Malvern).

\subsection{Biological test}

\subsubsection{Antimicrobial test}

The citrus limon leaf extract, silver nitrate and the silver nanoparticle was studied for their antibacterial and antifungal effect against human pathogen microbial strain including two gram (-) bacteria (Pseudomonas Aeruginosa ATCC 27853, Escherichia coli ATCC 25922), one (+) bacteria (Staphylococcus aureus ATCC 25923) and one fungi (Candida albicans ATCC 10231), which were kindly given by the laboratory of biology of Ain Temouchent university (Algeria) utilising agar well diffusion technique as reported by Khane et al. with some modification [20].

Inoculated Mueller-Hinton agar and Sabouraud dextrose plates were swabbed with $10^{6} \mathrm{CFU} / \mathrm{mL}(0.5$ McFarland standards) bacterial cultures and fungi, respectively. Then, the agar was pierced with $6 \mathrm{~mm}$ wells by a sterilized cork borer and each well was filled with $100 \mu \mathrm{L}$ of each tested simple as well as the sterilizing distillate water has been used as a negative control to confirm this technique. To express antimicrobial activity, the inhibitory zone formed around the simple was measured after $24 \mathrm{~h}$ of incubated of bacteria at $37^{\circ} \mathrm{C}$ and fungi at $30^{\circ} \mathrm{C}$. To ensure the results, each test was repeated three times. 


\subsubsection{Antioxidant test}

AgNPs and citrus limon leaf extract was examined for their antioxidant capacity using the DPPH Free Radical Scavenging technique [21], utilizing ascorbic acid as a reference and methanol as a Ascorbic acid was used as a reference and methanol was used as a control test.

$2 \mathrm{ml}$ DPPH methanolic solution $(4 \mathrm{mM})$ was mixed with $1 \mathrm{ml}$ of different concentrations of methanolic solution of lemon leaf extract, silver nanoparticle, and ascorbic acid standard. This mixture was then shaken before being kept at room temperature for an hour in a dark place. Then, the absorbance (A) of every solute is measured at $517 \mathrm{~nm}$ by a spectrophotometer UV-visib. The antiradicalaire activity is expressed by the value of the percentage of inhibition (\% I) using the next equation:

$\left.\mathrm{I} \%=\left[\left(\mathrm{A}_{\text {control test }}-\mathrm{A}_{\text {simple tested }}\right) / \mathrm{A}_{\text {control test }}\right)\right] \mathrm{x} 100$

The $\mathrm{IC}_{50}$ value was also used to determine the antioxidant property, which was explained as the concentration of the test simple that might inhibit $50 \%$ of the DPPH radicals.

\section{RESULTS AND DISCUSSION}

A bioactive silver nanoparticle was synthesized in this study by utilizing an aqueous solution of citrus lemon leaves as a natural reduction agent, and spectroscopic analysis was performed out to establish the production of AgNPs and their properties.

\subsection{Spectroscopy Analysis}

\subsubsection{UV-Visible spectra}

Lemon leaf aqueous extract mixed with silver nitrate formed green AgNPs, which were recognized by the color change from yellow to brown, and this is probably because to the excitation of silver's free electrons, indicating that the silver ion reduces to elemental silver and eventually to silver nanoparticles when exposed to biomolecule exist in the plant extract [22-23]. The change in optical properties of $\mathrm{AgNO}_{3}$ was clearly displayed in the UV-Vis spectra, with a remarkable peak at $475.2 \mathrm{~nm}$ relating to surface plasmon resonance (SPR) band. The same phenomenon was demonstrated by other researcher [24-25].

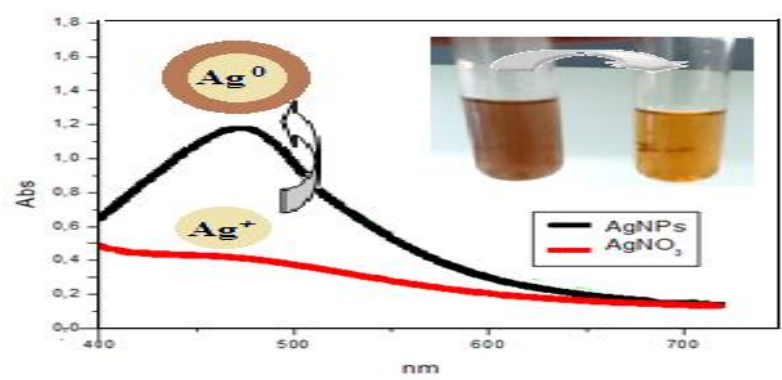

Figure $1 \mathrm{UV}-\mathrm{V}$ is spectra of AgNPs follows color change after the mix of citrus limon leaf extract with silver nitrate.

\subsubsection{FTIR spectroscopy}

As showing in Fig.2, The comparison between the two spectra FTIR of Citrus lemon leaf extract and AgNPs was indicated the bioactive molecule exist in the leaf extract concerned in the bioreduction and stabilization of silver ion to silver nanoparticles. The FT-IR spectra of lemon leaf extract (fig.2a) showed absorption peaks at $1100 \mathrm{~cm}^{-1}$ assigned to $\mathrm{C}-\mathrm{O}$ of polyols such the flavonoïdes, and polysaccharides which confirm the existence of phenolic compounds as well as the band of vibration located towards $1300 \mathrm{~cm}^{-1}$ attributed to the $\mathrm{C}-\mathrm{H}$ of aromatic cycle. The intense band at $1509 \mathrm{~cm}^{-1}$ represented the secondary amide $(\mathrm{N}-\mathrm{H})$ and $\mathrm{O}-\mathrm{H}$ stretching of alcohol, carboxylic acid and phenolic compounds appeared at $3369 \mathrm{~cm}^{-1}$ [26].

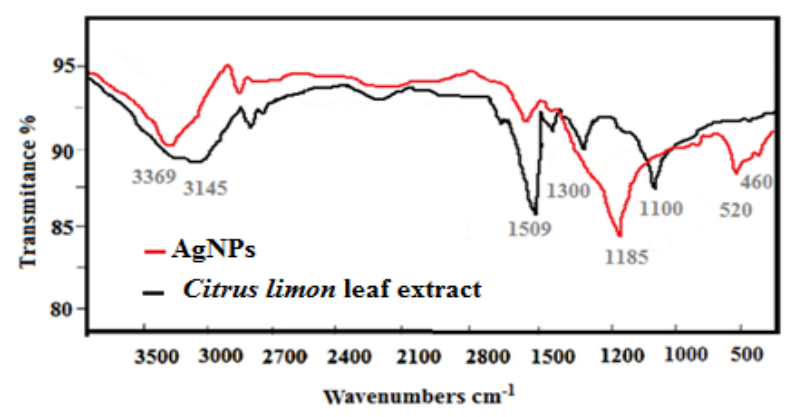

Figure 2 FT-IR spectra of silver nanoparticle and citrus lemon leaf extract.

According to change of absorption peaks of the FT-IR spectrum (fig.2b) after the formation of the silver nanoparticle, this photochemical compound present in citrus limon leaves extract including the flavonoids, phynolic acid, tannic acid, and citric acid served as a naturel capping or stabilizing agent as reported in some previous research [27-29]. 


\subsubsection{Zeta potential}

The surface charge of the produced AgNPs was determined using the zeta potential value, which indicated their stability [30,31]. As illustrated in fig 3 and table 1, the AgNPs using citrus limon leaf extract exhibit a negative charge $-21.8 \mathrm{mV}$ [32] which gives the repulsive force as an electrostatic stabilization.

Table 1. The zeta potential values of AgNPs.

\begin{tabular}{ccc}
\hline $\mathrm{T}$ & Conductivity & $\begin{array}{c}\text { Zeta potential } \\
(\mathrm{ZP})\end{array}$ \\
& & $\mathrm{mV}$ \\
${ }^{\circ} \mathrm{C}$ & $\mathrm{mS} / \mathrm{cm}$ & -21.8 \\
25 & 0.16 & \\
\hline
\end{tabular}

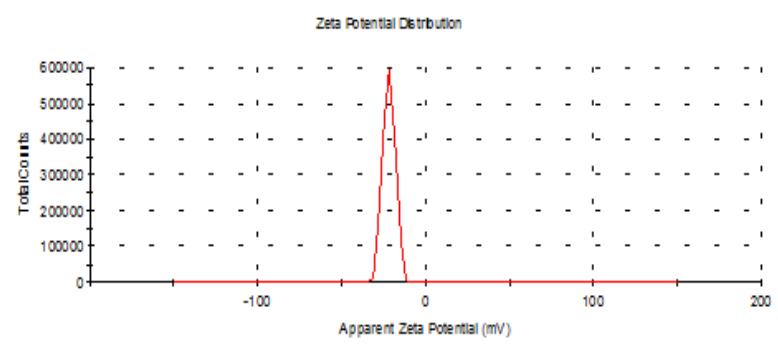

Figure 3 Zeta potential analysis of AgNPs prepared using Citrus Limon leaf extract.

\subsubsection{SEM-EDX spectroscopy}

the results of SEM micrographs was revealed that the silver nanoparticule synthesis using aqueous extract of lemon leaf had a spherical shaped and diffrent size from 35 to 82 nanometers. The EDX spectrum (Fig 4) was confirmed the production of purity AgNPs by noted a two pick with high percent value which was attributed to $\mathrm{Ag}$ at 3.60 and $7.63 \mathrm{KeV}$.

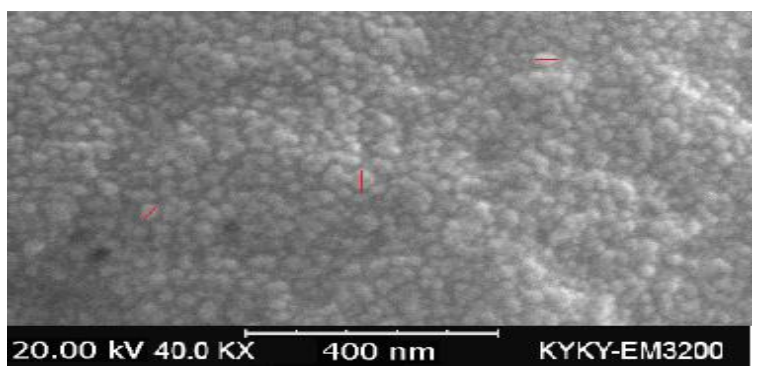

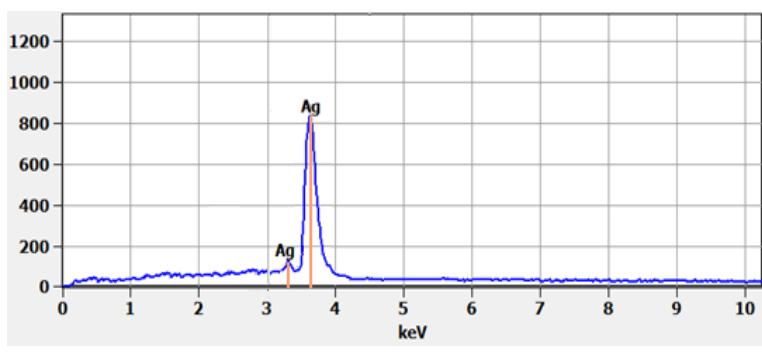

Figure 4 a) scanning electron microscopy imaging and b) EDX of AgNPs.

\subsection{Biological test results}

\subsubsection{Antibacterial and Antifungal Activity}

Table 2. Antimicrobial activity of AgNPs.

\begin{tabular}{|c|c|c|c|c|}
\hline \multirow{2}{*}{} & \multicolumn{3}{|c|}{ pathogens bacterial } & \multirow{2}{*}{ fungi } \\
\cline { 2 - 4 } & $\begin{array}{c}\text { Gram } \\
(+)\end{array}$ & \multicolumn{2}{|c|}{ Gram (-) } & \\
\hline & $\begin{array}{c}\text { S. } \\
\text { aureus }\end{array}$ & $\begin{array}{c}\text { P.aerugin } \\
\text { osa }\end{array}$ & E.coli & $\begin{array}{c}\text { C. } \\
\text { albicans }\end{array}$ \\
\hline AgNO $_{3}$ & $/$ & $/$ & $/$ & $/$ \\
\hline $\begin{array}{c}\text { Citrus } \\
\text { limon leaf } \\
\text { extract }\end{array}$ & 13 & 0 & 0 & 20 \\
\hline \multirow{2}{*}{\begin{tabular}{c} 
AgNPs \\
\cline { 2 - 5 }
\end{tabular}} & 25 & 12 & 13 & \multirow{2}{*}{3} \\
\hline $\begin{array}{c}\text { Control } \\
\text { negative }\end{array}$ & - & - & - & \\
\hline
\end{tabular}

\section{-No inhibition zone}

The silver nanoparticle and the citrus limon leaf extract was tested for their antimicrobial capability against three pathogenic bacteria species $(P$. Aeruginosa, E. coli, S. aureus) and one fungi ( $C$. albicans) using well agar diffusion method as reported in Table 2.

According to the scientific report, silver nitrate has got no antibacterial activity at smaller concentration; silver synthesis can be produced at lower doses of AgNO3 [33-34]. In addition, the antibacterial assay findings demonstrated that the silver nanoparticle had high or moderate action against the bacterium tested. The gram (+) bacteria were more vulnerable to AgNPs than gram bacteria, probably due to their structure 
[35]. Furthermore, the silver nanoparticle synthetis employing citrus limon leaves extract demonstrated remarkable antifungal potential [36-38]. The same findings was obtained by Kim et al. [39], and Lee et al. [40]. The sensitivity of this bacteria and fungi is due to the phenolic compounds and flavonoids [41] cover the surface of $\mathrm{AgNO}_{3}$ after the bioreduction of silver using citrus limon plant extract which give a synergistic combination.

\subsubsection{Antioxidant Activity results using DPPH method}

DPPH scavenging experiment was employed to test the antioxidant effect of AgNPs and the citrus limon leaf extract at various concentrations and expressed results with percentage of inhibition and $\mathrm{IC}_{50}$ as reported in Table 3 and Figure 5.

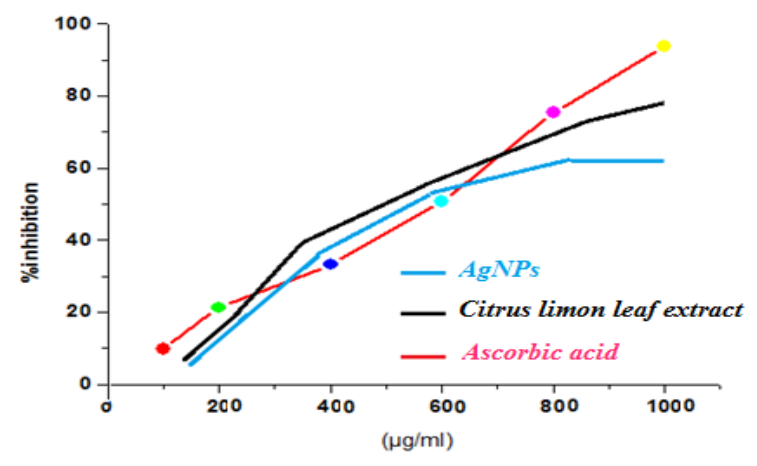

Figure 5 Percentage of inhibition of DPPH free radical with tested simples.

Table 3. The antioxydant results.

\begin{tabular}{|c|c|c|c|}
\hline & $\begin{array}{c}\text { Citrus limon } \\
\text { leaf extract }\end{array}$ & AgNPs & $\begin{array}{c}\begin{array}{c}\text { Ascorbic } \\
\text { acid }\end{array} \\
\end{array}$ \\
\hline $\begin{array}{l}\text { Percentage of } \\
\text { inhibition of } \\
\text { DPPH (en\%) }\end{array}$ & 54.20 & 53.86 & 58,5 \\
\hline IC50 $(\mathrm{mg} / \mathrm{ml})$ & 0.626 & 0.424 & 0.425 \\
\hline
\end{tabular}

Antioxidant activity increased with the increasing of the concentration and The reducing ability of DPPH using silver nanoparticle was great than citrus limon leaf aqueous extract and significantly higher than that of a standard antioxidant (ascorbic acid) because arcitucture and size of nanoparticle. The antioxidanr ability of silver nanoparticle was because the antioxidant metabolites exist in the surface of silver nanoparticle [42-43].

\section{CONCLUSION}

According to the results of this work, the AgNPs were effectively produced using citrus limon leaf extract, which is reported as a simple, low cost and respectful procedure for the environment. The propriety of these silver nanoparticles was validated by spectroscopy analysis which indicated that the bioactive photochemical compound found in the citrus lemon leaf extract was responsible for the bioreduction and stabilization of AgNPs. The silver nanoparticles synthesized were manly spherical with a negative surface charge and high stability. Furthermore, these AgNPs exhibited an antibacterial and antioxidant capability which confirms their theurapitic propriety.

\section{REFERENCES}

[1] J. Y. Song, and B. S. Kim, Rapid biological synthesis of silver nanoparticles using plant leaf extracts, Bioprocess Biosyst. Eng. 32, 79-84, 2009. doi: 10.1007/s00449-008-0224-6)

[2] M. A. Albrecht, C. W. Evans, and C. L. Raston, Green chemistry and the health implications of nanoparticles, Green Chem. 8, 417-432, 2006. DOI: https://doi.org/10.1039/B517131H

[3] A. K. Mittal, Y. Chisti, and U. C. Banerjee, Synthesis of metallic nanoparticles using plant extracts, Biotechnol. Adv. 31, 346-356, 2013. doi: 10.1016/j.biotechadv.2013.01.003)

[4] H. Singh, J. Du, P. Singh, T.H. Yi, Ecofriendly synthesis of silver and gold nanoparticles by Euphrasia officinalis leaf extract and its biomedical applications, Artif Cells Nanomed Biotechnol. 46(6):1163-1170, 2018. doi: 10.1080/21691401.2017.1362417.)

[5] H. P. Borase, B. K. Salunke, R. B. Salunkhe, C.D. Patil, J.E. Hallsworth, B.S. Kim, S.V. Patil, Plant extract: a promising biomatrix for ecofriendly, controlled synthesis of silver nanoparticles, Appl Biochem Biotechnol. 173(1):1-29, 2014. doi: 10.1007/s12010-014-0831-4.)

[6] M. Singhal, S. Chatterjee, A. Kumar, A. Syed, A.H. Bahkali, N. Gupta, S. Nimesh, Exploring the Antibacterial and Antibiofilm Efficacy of Silver Nanoparticles Biosynthesized Using Punica granatum Leaves, Molecules. 23, 
26(19):5762, 2021. doi: 10.3390/molecules26195762.)

[7] D. Mubarak Ali, N. Thajuddin, K. Jeganathan, M. Gunasekaran, Plant extract mediated synthesis of silver and gold nanoparticles and its antibacterial activity against clinically isolated pathogens, Colloids Surf B Biointerfaces. 1;85(2):360-5, 2011. doi: 10.1016/j.colsurfb.2011.03.009.

[8] R. Sankar, P. Manikandan, V. Malarvizhi, T. Fathima, K.S. Shivashangari, V. Ravikumar, Green synthesis of colloidal copper oxide nanoparticles using Carica papaya and its application in photocatalytic dye degradation, Spectrochimica Acta Part A: Molecular and Biomolecular Spectroscopy. 121:746-50, 2014. https://doi.org/10.1016/j.saa.2013.12.020.

[9] R. Javed, M. Zia, S. Naz, et al., Role of capping agents in the application of nanoparticles in biomedicine and environmental remediation: recent trends and future prospects, $\mathbf{J}$ Nanobiotechnol. 18, 172, 2020. https://doi.org/10.1186/s12951-020-00704-4

[10] O. A. Samson, U. Kenneth, A. A. Paul, C. N. Assumpta, M. E. Paul, S. Botha, A. Ishaq, M. Maaza, Fabian I. Ezema, Biogenic synthesis and antibacterial activity of controlled silver nanoparticles using an extract of Gongronema Latifolium, Materials Chemistry and Physics, 237,2019.Doi:10.1016/j.matchemphys.2019.121 859.

[11] O. A. Samson, U. Kenneth, A. A. Paul, C. N. Assumpta, U. Nwankwo, S. B. Subelia, M. Ejikeme Paul, A. Ishaq, M. Maaza, I. Ezema Fabian, Biosynthesis of silver nanoparticles using bitter leave (Veronica amygdalina) for antibacterial activities, Surfaces and Interfaces, Volume 2019, https://doi.org/10.1016/j.surfin.2019.100359.

[12] Y. Mohanta, S. Panda, K. Biswas, A. Tamang, J. Bandyopadhyay, D. De et al., Biogenic synthesis of silver nanoparticles from Cassia fistula (Linn.): in vitro assessment of their antioxidant, antimicrobial and cytotoxic activities, IET Nanobiotechnol. 10, 438-444, 2016. doi: 10.1049/iet-nbt.2015.0104

[13] Y. Mohanta, S. Singdevsachan, U. Parida, S.Panda, T. Mohanta, and H. Bae, (b). Green synthesis and antimicrobial activity of silver nanoparticles using wild medicinal mushroom Ganoderma applanatum (Pers.) pat. from similipal biosphere reserve. Odisha, India, IET Nanobiotechnol. 10, 184-189, 2016. doi: 10.1049/iet.

[14] J. S. Kim, E. Kuk, K. N.Yu, J. H.Kim, S. J. Park, H. J. Lee, et al., Antimicrobial effects of silver nanoparticles, Nanomed. Nanotechnol. Biol. Med. 3, 95-101, 2007. doi: 10.1016/j.nano.2006.12.001

[15] D. Nayak, S. Pradhan, S. Ashe, P. R.Rauta, and B.Nayak, Biologically synthesised silver nanoparticles from three diverse family of plant extracts and their anticancer activity against epidermoid A431 carcinoma, J. Colloid Interface Sci. 457, 329-338, 2015. doi: 10.1016/j.jcis.2015.07.012

[16] G. Débuigine et F. Couplan, Petit Larousse des plantes qui guérissent. Ed : Larousse, Paris. 895 p. 2008.

[17] A. Zayed, M. T.Badawy, \& M. A. Farag, Valorization and extraction optimization of Citrus seeds for food and functional food applications. Food Chemistry, 355, 129609, 2021.

https://doi.org/10.1016/j.foodchem.2021.129609

[15] M. Klimek-Szczykutowicz, A. Szopa, H.Ekiert, Citrus limon (Lemon) Phenomenon-A Review of the Chemistry, Pharmacological Properties, Applications in the Modern Pharmaceutical, Food, and Cosmetics Industries, and Biotechnological Studies, Plants. 9(1):119, 2020. https://doi.org/10.3390/plants9010119

[19] S.P.Minal, S.Prakash, Laboratory analysis of $\mathrm{Au}-\mathrm{Pd}$ bimetallic nanoparticles synthesized with Citrus limon leaf extract and its efficacy on mosquito larvae and non-target organisms, Sci Rep $\quad 10, \quad 21610, \quad 2020$. https://doi.org/10.1038/s41598-020-78662-y.

[20] Y. Khane , L. Belarbi, B. Mouffok, Synthesis, characterization of poly(ester-amide) and evaluation of their antimicrobial activity, Biointerface Research in Applied Chemistry Journal, 6: 2, 1104-1111, 2016 
[21] A. Lakhdari, L. Sakhri, Y. Khane, A. M. Lakhdar, A. Kemassi, N. Bouras, Evaluation of drying effect on the composition of the essential oil isolated from aerial parts of Pituranthos chloranthus from southern Algeria and their biological activities, Biocatalysis and Agricultural Biotechnology, 30-101844,2020, DOI: 10.1016/j.bcab.2020.101844

[22] S.P. Chandran, M. Chaudhary, R. Pasricha, A. Ahmad, M. Sastry, Synthesis of gold nanotriangles and silver nanoparticles using aloe vera plant extract. Biotechnol Progr 22(2):577583, 2006. doi:10.1021/bp0501423

[23]K.Nahar, D.C.Yang, E.J.Rupa, Mst.Khodeza Khatun, S.M. Al-Reza, Eco-friendly synthesis of silver nanoparticles from Clerodendrum viscosum leaf extract and its antibacterial potential. Nanomed Res J, 5(3): 276-287, 2020. DOI: $10.22034 /$ nmrj.2020.03.008

[24]V. R.Selvaraj Raja,T. Varadavenkatesan, Green biosynthesis of silver nanoparticles using Calliandra haematocephala leaf extract, their antibacterial activity and hydrogen peroxide sensing capability. 10: 253-261. 2015.

[25] P.C. Nagajyothi, K.D. Lee, Synthesis of plantmediated silver nanoparticles using Dioscorea batatas rhizome extract and evaluation of their antimicrobial activities, J. Nanomater. 2011.

[26] H. Yan, D. Zhiyun, L. Huibin, J. Z. Tang Qianfa, et al., Green synthesis of silver nanoparticles by Chrysanthemum morifolium Ramat. Extract and their application in clinical ultrasound gel, Int $\mathbf{J}$ Nanomedicine.8: 1809-1815, 2013.

[27] S.K. Sivaraman, I. Elango, S. Kumar, V. Santhanam, A green protocol for room temperature synthesis of silver nanoparticles in seconds, Curr. Sci. 97(7), 1055-1059, 2009.

[28] S. Vasantharaj, N. Sripriya, M. Shanmugavel, E. Manikandan, et al., Surface active gold nanoparticles biosynthesis by new approach for bionanocatalytic activity, J. Photochem. Photobiol. B 179, 119-125, 2018.

[29] D. Philip, C. Unni, S.A. Aromal, V.K. Vidhu, Murraya koenigii leaf-assisted rapid green synthesis of silver and gold nanoparticles, Spectrochim. Acta A 78(2), 899-904, 2011.
[30] B.D. Chithrani, A.A. Ghazani, W.C.W Chan, Determining the size and shape dependence of gold nanoparticle uptake into mammalian cells, Nano Lett.6:662-668, 2006.

[31] J. B.Amit Kumar Mittal, S. Kumar, U. C. Banerjee, Biosynthesis of silver nanoparticles: elucidation of prospective mechanism and therapeutic potential, Journal of Colloid and Interface Science: 1-33, 2013.

[32] T. C. Prathna, N.Chandrasekaran, A. M.Raichur, \& A.Mukherjee, Biomimetic synthesis of silver nanoparticles by Citrus limon (lemon) aqueous extract and theoretical prediction of particle size, Colloids and Surfaces B: Biointerfaces, 82(1), $152-159,2011$. doi:10.1016/j.colsurfb.2010.08.036.

[33] S.R. Kumar Pandian, V. Deepak, K. Kalishwaralal, P. Viswanathan, S. Gurunathan, Mechanism of bactericidal activity of silver nitrate - a concentration dependent bi-functional molecule, Braz J Microbiol. 41(3):805-809, 2010. doi:10.1590/S1517-83822010000300033

[34] K. Kalimuthu, R. S. Babu, D. Venkataraman, M. Bilal, S. Gurunathan, Biosynthesis of silver nanocrystals by Bacillus licheniformis, Colloids and Surfaces B: Biointerfaces, 65:1, 2008. doi: 10.1016/j.colsurfb.2008.02.018.

[35] S. R.Kumar Pandian, V.Deepak, K.Kalishwaralal, P.Viswanathan \& S.Gurunathan, Mechanism of bactericidal activity of silver nitrate - a concentration dependent bi-functional molecule. Brazilian journal of microbiology, Brazilian Society for Microbiology, 41(3), 805-809, 2010. https://doi.org/10.1590/S1517838220100003000 $\underline{33}$

[36] J.U. Ewansiha, S.A. Garba, G.Musa, S.Y. Daniyan, , M. B. Busari, et al., Preliminary Phytochemical and Antimicrobial Activity of Citrus x limon (L) Burm. f. (lemon) Leaf Extract against Some Pathogenic Microorganisms. Journal of Applied Life Sciences International, 6(4), 1-10, 2016. https://doi.org/10.9734/JALSI/2016/27579.

[37] L. Runze, C. Jie, C. C. Thomas, W. Xin, S. Y. Joshua, M. R, Peter, Synergistic reaction against bacteria, Proceedings of the National Academy of 
Sciences, 113 (48) 13612-13617, 2016. DOI: 10.1073/pnas.1611193113.

[38] S. Tyagi, P. K. Tyagi, D. Gola, N. Chauhan, and R. K. Bharti, Extracellular synthesis of silver nanoparticles using entomopathogenic fungus: characterization and antibacterial potential, $\mathrm{SN}$ Applied Sciences, 1(12): 1-9, 2019.

[39] Kim, Keuk-Jun, W.S. Sung, S.K. Moon, J.S. Choi, J.G. Kim, D.G. Lee, Anti-fungal effect of silver nanoparticles on dermatophytes, J. Microbiol. Biotechnol. 18, 482-1484. 2008.

[40] J. Lee, K.J. Kim, W.S. Sung, J.G. Kim, D.G. Lee, The Silver Nanoparticle (Nano-Ag) : a New Model for Anti-fungal Agents, InTech, 295-308. 2010.

[41] M. E. A. Dib, H. Allali, A. Bendiabdellah, N.Meliani, \& B.Tabti, Antimicrobial activity and phytochemical screening of Arbutus unedo L, Journal of Saudi Chemical Society, 17(4), 381385. 2013.

[42] Z. Zhuo, X. Wanpeng, H. Yan, N. Chao, Z. Zhiqin, Antioxidant activity of Citrus fruits, Food Chemistry, 196: 885-896, 2016. https://doi.org/10.1016/j.foodchem.2015.09.072.

[43] Y.Miyake, K.Yamamoto, Y.Morimitsu, T.Osawa, Isolation of C-Glucosylflavone from Lemon Peel and Antioxidative Activity of Flavonoid Compounds in Lemon Fruit, Journal of Agricultural and Food Chemistry,45(12):46194623, 1997. doi: 10.1021/jf970498x. 